\title{
Caracterização morfológica de isolados de Cryptosporiopsis perennans em diferentes meios de cultura
}

\author{
Amauri Bogo ${ }^{1}$, Marta A. Maffioletti ${ }^{1}$, Rosa M. V. Sanhueza ${ }^{2}$ \& Ricardo T. Casa $^{1}$ \\ ${ }^{1}$ Departamento de Fitotecnia, Centro de Ciências Agroveterinárias, Universidade do Estado de Santa Catarina, Cx. Postal 281, \\ 88502-970, Lages, SC, Brasil; ${ }^{2}$ Embrapa Uva e Vinho, Cx. Postal 1513, 95.200-000, Vacaria, RS, Brasil
}

Autor para correspondência: Amauri Bogo, e-mail: a2ab@cav.udesc.br

\section{RESUMO}

O crescimento micelial e a esporulação de nove isolados de Cryptosporiopsis perennans foram avaliados nos meios de cultura batata-dextrose-ágar acidificado (BDA-acid), ágar extrato de malte (AEM) e V8-ágar (V8) sob o regime de fotoperiodo de $12 \mathrm{~h}$ a $21^{\circ} \mathrm{C}$. Discos de $5 \mathrm{~mm}$ de diâmetro, retirados de colônias crescidas em meio BDA por 14 dias, foram transferidos para placas de Petri contendo 20 $\mathrm{mL}$ de cada meio. Morfologia das colônias, crescimento micelial, esporulação e dimensão dos esporos foram determinadas ao $13^{\circ}$ dias de incubação. Observou-se que os efeitos dos meios de cultura variaram dependendo do isolado. Verificou-se crescimento micelial e produção de conídios em todos os meios testados, porém com uma ampla variação de aspecto e coloração de colônias. Maior crescimento micelial e produção de conídios foram observados nos meios de cultura V8 e AEM, para a maioria dos isolados de C. perennans avaliados. Em todos os meios de cultura todos isolados produziram microconídios fusiformes.

Palavras-chave: Malus domestica, maça, podridão olho-de boi.

\begin{abstract}
Morphological characterization of Cryptosporiopsis perennans isolates in different culture media

The mycelial growth and conidial production of nine isolates of Cryptosporiopsis perennans were evaluated on the culture media of potato-dextrose-agar acidified (PDA-acid), malt extract agar (MEA) and V8-agar (V8) under 12 hours of photoperiod at $21^{\circ} \mathrm{C}$. Five mmdiameter disks taken from colonies grown for 14 days on PDA medium under 12 hours of photoperiod at $21^{\circ} \mathrm{C}$ were transferred to Petri dishes with $20 \mathrm{~mL}$ of each medium. Colonial morphology, mycelial growth, sporulation and spore dimension were evaluated after 13 days of incubation. The effect of the culture media varied according to isolates. Mycelial growth and conidial production were observed in all tested media. The culture medium V8 was the best medium tested for mycelial growth and conidial production, followed by MEA for all $C$. perennans isolates. In all culture media the isolates presented a fusiform conidial shape.
\end{abstract}

Keywords: Malus domestica, apple, bull's-eye rot.

A podridão "olho-de-boi em frutos", e o cancro de ramos da macieira, associados à infecção pela fase anamórfica de Cryptosporiopsis perennans (Zeller \& Childs) Wollenw. (Kienholz, 1939) [teleomorfo Neofabreae perennans Kienholz; sin. Pezicula perennans (Kienholz Dugan, R.G. Roberts \& G.G. Grove foram descritas no Brasil em 1996 e atualmente encontram-se disseminadas em todas as regiões produtoras de maçã do Rio Grande do Sul, Santa Catarina e Paraná, causando perdas de até 16\% na cultivar Fuji (Sanhueza, 2002).

As ambigüidades taxonômicas surgiram apartir dos trabalhos de Kienholz (1939), que utilizou para descrever a espécie $N$. perennans características de apotécios obtidos em inoculação artificial em macieiras. Já Boerema \& Verhoeven (1972) consideraram C. perennans e C. malicorticis como sinônimo de C. curvispora, considerando esse o correto nome da fase anamórfica de $N$. malicorticis. Sutton (1980) não considerou a espécie $C$. curvispora utilizada por Boerema \& Verhoeven (1972), utilizando somente $C$. perennans como sinônimo de C. malicorticis. Estes fungos têm sido considerados diferentes espécies de acordo com características culturais, curvatura dos macroconídios, fisiologia e sintomas da doença em maçã nos EUA. (Miller, 1932; Kienholz, 1939; Dugan et al., 1993). Jong et al. (2001) demonstraram com técnicas moleculares que o complexo de agentes causais [...] da podridão "olho-de-boi" é constituído por quatro espécies do gênero Neofabraea: $N$. perennans Kienholz, N. malicorticis H.S. Jacks., N. alba (E.J. Guthrie) Verkley e e uma espécies não descrita de Neofabraea sp. No Brasil, somente foi constatada a fase anamórfica de $C$. perennans até o presente, mas é provável que, como ocorre em outras regiões produtoras de maçãs do mundo, estudos mais abrangentes sobre os isolados associados a esta doença possam identificar outras espécies, pois as características morfológicas e fisiológicas que diferenciam essas espécies são pouco claras. A identificação é baseada em critérios convencionais tênues e a alta variabilidade morfológica interfere na definição precisa da posição taxonômica dos isolados associados ao sintoma citado, originando relatos conflitantes (Gariépy et al., 2003). 
Apesar da importância do patógeno existem poucas publicações sobre a caracterização de $C$. perennans, e pouco se conhece do efeito das condições climáticas, variações genéticas e biologia do patógeno e do tipo de resistência do hospedeiro. Para o desenvolvimento de estudos sobre o patógeno é fundamental o conhecimento de características morfológicas de colônias, micélio e conídios, bem como fisiológicas, como composição química dos meios de cultura que determina a eficiência da esporulação e crescimento micelial dos fitopatógenos (Dhingra \& Sinclair, 1995).

Dugan et al. (1993) compararam a morfologia de colônias e conídios de isolados de $C$. perennans e $C$. curvispora e constataram que os macroconídios de $C$. curvispora produzidos em meio de cultura BDA eram curvos, unicelulares, hialinos e mediam 3-6 $\mu \mathrm{m}$ por $10,5-17,7 \mu \mathrm{m}$, enquanto que os microconídios eram retos, unicelulares e mediam $1,5-2,5$ por 5-8 $\mu \mathrm{m}$, diferindo da espécie $C$. perennans, além de uma grande quantidade de estromas pulverulentos em culturas mais velhas. No meio de cultura V8-aveia, a largura média dos conídios de C. curvispora e C. perennans foi de 1,9 e 1,6 $\mu \mathrm{m}$, respectivamente e somente $C$. perennans produziu sinêmios sem ápices ramificados. Diferenças morfológicas e fisiológicas de isolados de espécies do gênero Cryptosporiopsis em meio de cultura pode ter significância taxonômica. No meio de cultivo ágar extrato de malte $2 \%$, isolados da espécie $N$. Fructigenum tiveram maior taxa de crescimento, comparados com isolados das espécies $N$. perennans e N. album (Henriquez et al., 2004). Neste trabalho avaliaram-se características morfológicas de colônias, crescimento micelial, produção e forma de conídios de nove isolados de C. perennans associados à podridão 'olho de boi' cultivados nos meios de cultura BDA acidificado, Extrato de Malte-ágar e Ágar suco V8.

Os trabalhos foram realizados nos laboratórios de Fitopatologia da Embrapa Uva e Vinho, em Vacaria/RS e do Centro de Ciências Agroveterinárias- CAV/UDESC, em Lages/SC. Os isolados de C. perennans foram obtidos de frutos com sistomas de podridão "olho-de-boi" em maçãs da cultivar Fuji de diferentes pomares e regiões do Sul do Brasil e pertencem à coleção da Embrapa Uva e Vinho (Tabela 1). Para o isolamento, os frutos foram desinfestados superficialmente com álcool etílico hidratado $92^{\circ}$ e lavados com água destilada estérilizada. Fragmentos de tecidos com a podridão "olho de boi" foram retirados das margens das lesões e colocados em meio de cultura BDA contido em placas de Petri. As placas foram mantidas a $21^{\circ} \mathrm{C}$ com fotoperiodo de 12 horas. Após o crescimento das colônias, culturas monospóricas de cada isolado foram transferidas para tubos de vidro com BDA e preservados a $4^{\circ} \mathrm{C}$.

As colônias dos isolados foram inicialmente cultivados em BDA e incubadas durante 14 dias com fotoperíodo de 12 horas e temperatura de $21^{\circ} \mathrm{C}$. Nas placas de Petri com os diferentes meios de cultura foi substituído um disco central com $5 \mathrm{~mm}$ de diâmetro por outro com o mesmo diâmetro com o micélio de cada isolado. As placas foram mantidas a $21^{\circ} \mathrm{C}$ com fotoperíodo de 12 horas.
Os meios de cultura testados formam: i. BDA acidificado - Batata-Dextrose-Ágar (10g de dextrose, $18 \mathrm{~g}$ de ágar, $300 \mathrm{~mL}$ de caldo de batata e $700 \mathrm{~mL}$ de água destilada) acidificado com ácido lático a $\mathrm{pH} 4,5$ antes de verter; ii. V8 - meio de ágar com suco V8 (200 mL de V8 (Campbel Soup Company), $3 \mathrm{~g}$ de $\mathrm{CaCO}_{3}, 17 \mathrm{~g}$ de ágar e $800 \mathrm{~mL}$ de água destilada) e iii. extrato de malte ágar ( $25 \mathrm{~g}$ de extrato de malte, $17 \mathrm{~g}$ de ágar e $1000 \mathrm{~mL}$ de água destilada).

As avaliações finais do diâmetro das colônias foram feitas aos $13^{\circ}$ dias de incubação com registro de dois diâmetros perpendiculares feitos com paquímetro digital (Mitutoyo) bem como aspecto e coloração de colônias. As avaliações de forma, dimensão (comprimento e largura média de 50 esporos por isolado e meio de cultura) e produção de conídios foram determinadas em um disco de $1,5 \mathrm{~cm}$ de diâmetro retirado da região central de cada colônia ao $13^{\circ}$ dia de incubação. Os conídios foram retirados dos discos de cada meio de cultura com bastão de vidro e água, e suspendidos em água destilada esterilizada com Tween-80, 0,001\%, e a contagem de conídios em câmara de Neubauer.

Os ensaios foram conduzidos em delineamento inteiramente casualisado com 5 repetições, sendo cada repetição constituída por uma placa de Petri. Os dados foram analisados como experimento fatorial ( 9 isolados e três meios de cultura). Foi realizado teste $\mathrm{F}$ seguido de contraste de médias $(\mathrm{p}<0,05)$ para as variáveis diâmetro das colônias e produção de conídios (Demétrio, 2001). Todas as pressuposições para a análise de variância foram devidamente testadas de acordo com Banzatto \& Kronza (2006).

Houve variação quanto a morfologia e coloração das colônias (Figura 1). As colônias nos três meios de cultura apresentavam margem lisa, micélio aéreo bem desenvolvido, medianamente cotonoso a cotonoso. Algumas colônias produziram micélio aéreo denso e floculoso com a presença de zonas concêntricas. A coloração do micélio aéreo variou de cinza-esverdeado a levemente rosado. Em algumas colônias foi observado com micélio central submerso avermelhado e margem levemente rosada (Figura 1, BDA-A-5). A maior

TABELA 1 - Origem dos isolados de Cryptosporiopsis perennans

\begin{tabular}{lllc}
\hline \hline $\begin{array}{l}\text { Origem dos } \\
\text { isolados }\end{array}$ & Código & Cultivar & $\begin{array}{c}\text { Data da } \\
\text { coleta }\end{array}$ \\
\hline Tainha/RS & Cp1 & Fugi & 2002 \\
Tainha/RS & Cp2 & Fugi & 2002 \\
Tainha/RS & Cp3 & Fugi & 2002 \\
Vacaria/RS & Cp4 & Fugi & 2002 \\
Friburgo/SC & Cp5 & Fugi & 2003 \\
Vacaria/RS & Cp6 & Fugi & 2002 \\
Vacaria/RS & Cp7 & Fugi & 2003 \\
Vacaria/RS & Cp8 & Fugi & 2003 \\
Friburgo/SC & Cp9 & Fugi & 2002 \\
\hline
\end{tabular}



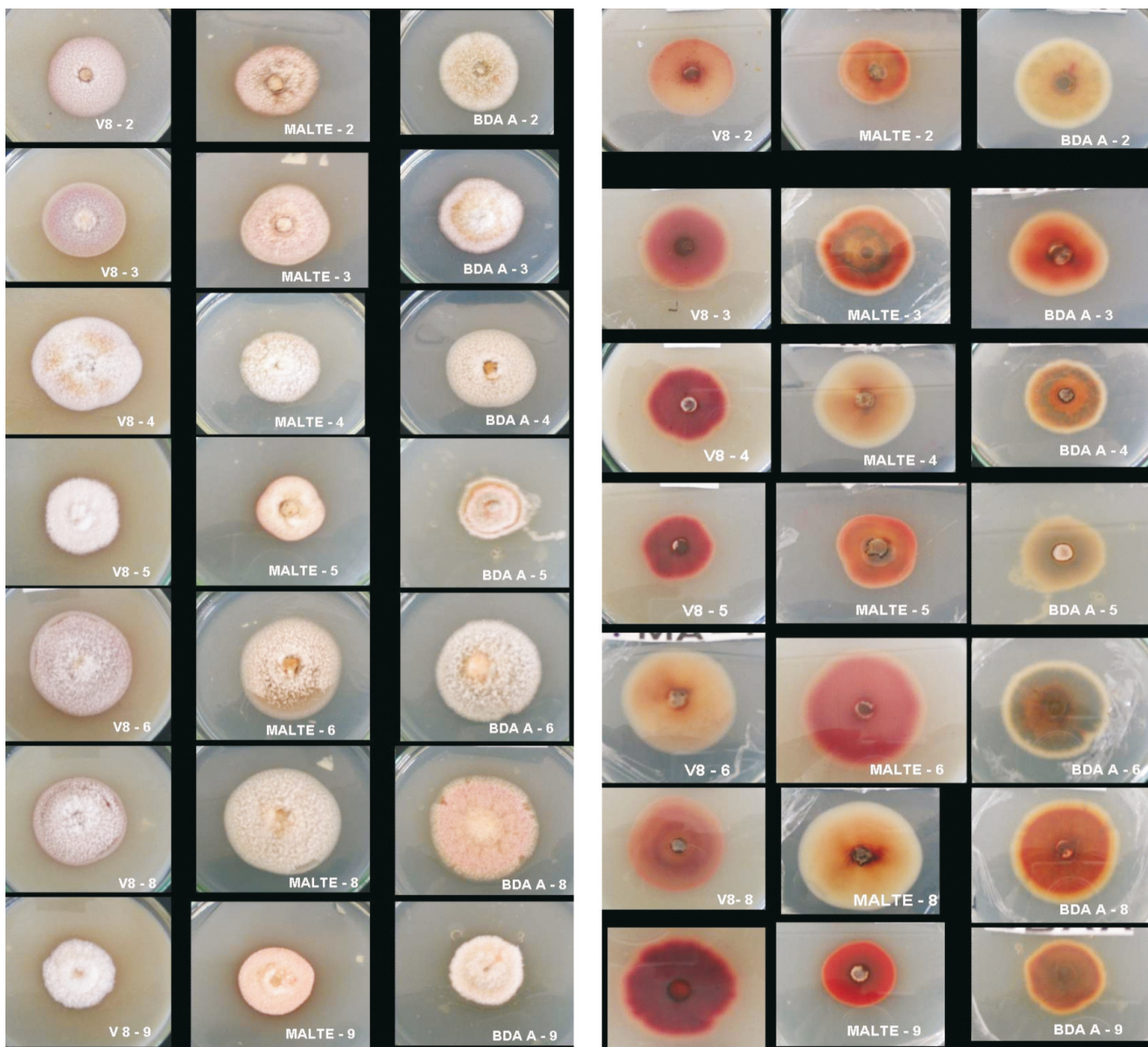

FIG. 1 - Aspecto e coloração de colônias (esquerda: parte superior das placas; direita: lado inverso das placas) de isolados de Cryptosporiopsis perennans, isolados de frutos de macieira, ao $13^{\circ}$ de incubação.

V8 (meio V8 ágar); MALTE (extrato de malte ágar); BDA A (batata-dextrose-ágar); 2, 3, 4, 5, 6, 7, 8 e 9 (número de isolados.

variação de coloração foi observada no lado inverso das colônias. No meio V8, variou de amarelo-avermelhado a vermelho-púrpura, no meio AEM de rosa à variações de laranja- avermelho a púrpura e no meio BDA-acid de cinzaesverdeado a vermelho alaranjado.

Nos três meios de cultura testados, não houve diferença significativa quando as dimensões médias de macroconídios e microconídios. As colônias produziram nos três meios de cultura macroconídios curvos, hialinos, unicelulares, com extremidades arredondadas à levemente

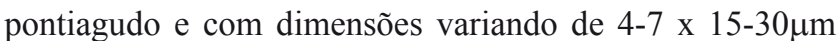
e microconídios cilíndricos, retos e alguns, levemente curvados nas pontas com ápice arredondado e dimensões variando de $1-2 \times 5-8 \mu \mathrm{m}$.

Houve interação significativa entre os fatores isolados e meio de cultura de modo que foram realizados dois testes de média dentro de cada isolado e meio de cultura (Tabela 2). Houve diferença significativa quanto ao crescimento micelial e produção de microconídios $(\mathrm{p}<0,05)$ para os nove isolados de C. perennans nos meios de cultura avaliados (Tabela 2). No meio de cultura V8 foi observado o maior crescimento micelial das colônias para todos os isolados, exceto para $\mathrm{o}$ isolado 5, que teve o menor valor entre todos. $\mathrm{O}$ menor desenvolvimento micelial das colônias foi observado para o isolado 5 no meio de cultura BDA- acid (Tabela 2). Dos nove isolados avaliados somente os isolados 4, 5 e 9 não diferiram significativas no desenvolvimento micelial das colônias nos meios BDA-acid e AEM, e somente o isolado 6 não diferiu no seu crescimento micelial quando comparado nos meios de cultura AEM versus V8. Houve diferença significativa na quantidade de conídios produzidos pelos diferentes isolados no meio de cultura $\mathrm{V} 8$, destacando o isolado 2 com a maior 
TABELA 2 - Médias de crescimento micelial e produção de microconídeos de Cryptosporiopsis perennans em diferentes meio de cultura aos $13^{\circ}$ dias após a inoculação

\begin{tabular}{|c|c|c|c|c|c|c|}
\hline & \multicolumn{3}{|c|}{ crescimento } & \multicolumn{3}{|c|}{ esporulação } \\
\hline & \multicolumn{2}{|c|}{ micelial (mm) } & & \multicolumn{3}{|c|}{ microconídios $\times 10^{4} / \mathrm{mL}$} \\
\hline & \multicolumn{6}{|c|}{ meios de culturas } \\
\hline Isolados & BDA-acid & V8 & AEM & BDA & V8 & AEM \\
\hline 1 & $29,0 \mathrm{Bb}$ & $33,4 \mathrm{Ba}$ & $31,6 \mathrm{Ba}$ & $41,1 \mathrm{Cc}$ & $115,2 \mathrm{Ca}$ & $66,0 \mathrm{Cb}$ \\
\hline 2 & $30,9 \mathrm{Bb}$ & $34,5 \mathrm{Ba}$ & $30,0 \mathrm{Bb}$ & $23,7 \mathrm{Dc}$ & $186,0 \mathrm{Aa}$ & $95,7 \mathrm{Ab}$ \\
\hline 3 & $33,9 \mathrm{Aa}$ & $33,0 \mathrm{Ba}$ & $28,8 \mathrm{Bb}$ & $45,1 \mathrm{Cc}$ & $89,7 \mathrm{Da}$ & $77,0 \mathrm{Bb}$ \\
\hline 4 & $30,1 \mathrm{Bb}$ & $31,6 \mathrm{Bb}$ & $37,1 \mathrm{Aa}$ & $16,0 \mathrm{Ec}$ & $100,5 \mathrm{Da}$ & $32,7 \mathrm{Db}$ \\
\hline 5 & $17,1 \mathrm{Dc}$ & $27,8 \mathrm{Ca}$ & $23,5 \mathrm{Cb}$ & $27,0 \mathrm{Dc}$ & $66,2 \mathrm{~Eb}$ & $81,7 \mathrm{Ba}$ \\
\hline 6 & $34,1 \mathrm{Ab}$ & $39,6 \mathrm{Aa}$ & $38,6 \mathrm{Aa}$ & $79,0 \mathrm{Ab}$ & $94,2 \mathrm{Da}$ & $38,5 \mathrm{Dc}$ \\
\hline 7 & $25,6 \mathrm{Cb}$ & $33,7 \mathrm{Ba}$ & $32,0 \mathrm{Ba}$ & $47,5 \mathrm{Cc}$ & $126,1 \mathrm{Ca}$ & $64,2 \mathrm{Cb}$ \\
\hline 8 & $37,0 \mathrm{Aa}$ & $38,9 \mathrm{Aa}$ & $39,4 \mathrm{Aa}$ & $66,2 \mathrm{Bb}$ & $124,2 \mathrm{Ca}$ & $55,5 \mathrm{Cc}$ \\
\hline 9 & $20,0 \mathrm{Cc}$ & $28,2 \mathrm{Ba}$ & $24,5 \mathrm{Cb}$ & $30,7 \mathrm{Dc}$ & $145,5 \mathrm{Ba}$ & $81,0 \mathrm{Bb}$ \\
\hline CV\% & 6,2 & 4,9 & 4,7 & 11,2 & 9,4 & 7,8 \\
\hline
\end{tabular}

${ }^{1}$ BDA-acid= batata dextrose ágar acidificado; V8= V8-ágar; $\mathrm{AEM}=$ extrato de malte. Médias seguidas pela mesma letra maiúscula na coluna e minúscula na linha não diferem entre sí pelo teste de Tukey $(\mathrm{P}=0,05)$.

esporulação (Tabela 2). $\mathrm{O}$ meio de cultura V8 sob regime de fotoperíodo de 12 hs é o mais eficiente no crescimento micelial e produção do conídios de C. perennans.

Meio de cultura contendo alta concentração de carboidratos pode estimular o crescimento micelial, mas não a esporulação (Moore-Landecker, 1972). Já meios com baixo teor de carboidratos, mas com extratos vegetais, normalmente estimulam a esporulação de vários fungos (Dhingra \& Sinclair, 1995), sendo o que foi observado para C. perennans em relação ao meio V8 (Tabela 2).

A variabilidade do patógeno é confirmada pelos resultados obtidos por Dugan et al., 1993, que mostraram que o estímulo diferencial observado em alguns isolados, por um dos meios de cultura, nem sempre se mantem constante quando da variação de fotoperíodo. O maior estímulo ao desenvolvimento das colônias, bem como a produção de esporos, exercido pelos meios de culturas V8 e AEM, para a maioria dos isolados, justifica a sua escolha isoladamente ou associados, sendo recomendado o seu uso nos estudos futuros deste patógeno no Brasil.

\section{REFERÊNCIAS BIBLIOGRÁFICAS}

Boerema GH, Verhoeven AA (1972) Checklist for scientific names of common parasitic fungi. Series 1a: Fungi on trees and shrubs. Netherland Journal of Plant Pathology 78, Supplement 1.

Bonzatto PA, Kronza SN (2006). Experimentação Agrícola. $3^{\circ}$ ed. Jabuticabal SP. Funep.

Demétrio CGB (2001) Modelos lineares generalizados em experimentação agronômica. 46 Reunião Anual da Sociedade Internacional de Biometria e $9^{\circ}$ Simpósio de Estatística e
Experimentação Agronômica. ESALQ, Universidade de São Paulo. Piracicaba SP. p. 113.

Dhingra OD, Sinclair JB (1995) Basic Plant Pathology Methods. Boca Raton FL. Lewis Publishers.

Dugan FM, Grove GG, Roberts JD (1993) Comparative studies of Cryptosporiopsis curvispora and C. perennans. I. Morphology and pathogenic behavior. Mycologia 85:551-564..

Gariépy TD, Lévesque AC, Jong SN, Rahe JE (2003) Species specific identification of the Neofabraea pathogen complex associated with pome fruits using PCR and multiplex DNA amplification. Mycologia 107:528-536.

Henriquez JL, Sugar D, Spotts RA (2004) Etiology of bull's eye rot of pear caused by Neofabraea spp. in Oregon, Washington, and California. Plant Disease 88:1134-1138.

Jong SN, Levesque CA, Verkley GJM, Abeln ECA, Rahe JE, Braun PG (2001) Phylogenetic relatiowships among Neofabraea species causing tree cankers and bull's-eye rot of apple based on DNA sequencing of ITS nuclear rDNA, mitochondrial rDNA and the B-tubulin gene. Mycological Research 105:658-669.

Kienholz JR (1939) Comparative study of the apple anthracnose and perennial canker fungi. Journal of Agriculture Research 59:635-665.

Moore-Landecker E (1972) Fundamentals of the Fungi. London. Prentice-Hall.

Miller EV (1932) Some physiological studies of Gloeosporium perennans and Neofabraea malicorticis. Journal Agricultural Research 45:65-77.

Sanhueza RMV (2002) Ocorrência de Cryptosporiopsis perennans em macieiras "Fuji" no Sul do Brasil. Summa Phytopathologica 28:204-206.

Sutton BC (1980) The Coelomycetes. Fungi Imperfecti with pycnidia, acervuli and stromata. Kew UK. Commonwealth Mycological Institute. 